\title{
Development of a Dysphagia Screening Test for Preterm Infants (DST-PI)
}

\author{
Kyoung Moo Lee, MD, Young Tak Seo, MD \\ Department of Rehabilitation Medicine, Chungbuk National University College of Medicine, Cheongju, Korea
}

\begin{abstract}
Objective To explore both the early prediction and diagnosis of dysphagia in preterm infants as an important developmental aspect as well as the prevention of respiratory complications, we developed the simple and-easyto-apply Dysphagia Screening Test for Preterm Infants (DST-PI) to predict supraglottic penetration and subglottic aspiration.

Methods Fifty-two infants were enrolled in a videofluoroscopic swallowing study (VFSS) due to clinical suspicions of dysphagia. Thirteen items related to supraglottic penetration or subglottic aspiration were initially selected from previous studies for the DST-PI. Finally, 7 items were determined by linear logistic regression analysis. Cutoff values, sensitivity, specificity, and the area under the ROC curve (AUC) of the DST-PI for predicting supraglottic penetration or subglottic aspiration were calculated using a ROC curve. For inter-rater reliability, the kappa coefficient was calculated.

Results Seven items were selected: 'gestational age,' 'history of apnea,' 'history of cyanosis during feeding,' 'swallowing pattern,' 'coughs during or after feeding,' 'decreased oxygen saturation within 3 minutes of feeding,' and 'voice change after feeding.' The Spearman correlation coefficient between the DST-PI and the penetrationaspiration scale (PAS) was $0.807(\mathrm{p}<0.001)$. The sensitivity and specificity at different cutoff values for detecting supraglottic penetration and subglottic aspiration were $96.6 \%$ and $76.9 \%$ at 3.25 , and $88.9 \%$ and $75.8 \%$ at 6.25 , respectively.

Conclusion The DST-PI is a valid and reliable dysphagia screening test for supraglottic penetration or subglottic aspiration in preterm infants that is easy to apply in a clinical context.
\end{abstract}

Keywords Dysphagia, Premature infant, Screening test, Videofluoroscopic swallowing study, Aspiration

\section{INTRODUCTION}

Along with the developments in medicine, the survival rate of preterm infants has also increased from $9.4 \%$ in
1981 , to $10.6 \%$ in 1990 , and $12.0 \%$ in 2002 [1]. Forty to $72 \%$ of preterm infants suffer from dysphagia $[2,3]$ and there are increasing numbers of reported cases [4,5]. Appropriate swallowing procedures are important in the physi-

Received July 8, 2016; Accepted October 10, 2016

Corresponding author: Young Tak Seo

Department of Rehabilitation Medicine, Chungbuk National University Hospital, 776 1(il)sunhwan-ro, Heungdeok-gu, Cheongju 28644, Korea. Tel: +82-43-269-6227, Fax: +82-43-269-6228, E-mail: tak_sama@hanmail.net

ORCID: Kyoung Moo Lee (http://orcid.org/0000-0002-3191-8848); Young Tak Seo (http://orcid.org/0000-0002-4186-7327).

@ This is an open-access article distributed under the terms of the Creative Commons Attribution Non-Commercial License (http://creativecommons.org/ licenses/by-nc/4.0) which permits unrestricted noncommercial use, distribution, and reproduction in any medium, provided the original work is properly cited. Copyright $\odot 2017$ by Korean Academy of Rehabilitation Medicine 
cal and functional development of preterm infants, but dysphagia can lead to problems such as nutritional disorders, delayed development, and complications in the respiratory system $[6,7]$. The many causes of dysphagia in preterm infants include low birth weight, gastroesophageal reflux, neuromuscular disorders, genetic disorders, and respiratory infections [4,5,8-12].

Videofluoroscopic swallowing study (VFSS) is the standard diagnostic test for dysphagia [13]. However, its use is limited because of exposure to radiation and the preterm infants' low cooperation. Some studies report signs or symptoms of dysphagia, such as a decreased sucking ability, history of cyanosis or apnea, and desaturation or coughing during feeding [2,4,14-19]. Because of such problems, there are dysphagia screening tests for both adults and children [20-22], but there are few for preterm infants.

The early prediction and diagnosis of dysphagia are important for its treatment and to prevent complications. Therefore, we developed the simple and easy-to-use Dysphagia Screening Test for Preterm Infants (DST-PI), based on the reported signs and symptoms of dysphagia in clinical settings.

\section{MATERIALS AND METHODS}

\section{Subjects}

From March 2013 to February 2016, 52 infants were admitted to a neonatal intensive care unit receiving VFSS due to clinical suspicions of dysphagia. The following cases were included in the study: (1) VFSS performed due to suspicions of dysphagia, such as desaturation or cough during feeding, apnea, or recurrent pneumonia; (2) preterm infants whose gestational age was less than 37 weeks. The following cases were excluded (1) anatomic abnormality, such as a cleft lip or a cleft palate; (2) absence of the initial medical record due to transfer from another hospital. Seven cases were excluded because they were full-term infants, and three had no available initial medical record. This is a retrospective medical record review study that was approved by the Institutional Review Board.

\section{Study methods}

Initial assessment items

We selected the initial items from many studies: 'ges- tational age' [2,14], 'the Apgar score at 5 minutes' [23], 'body weight at birth' [10], 'history of ventilator usage' [17], 'history of pneumonia' [5], 'history of apnea' [19], 'history of cyanosis during feeding' [15], 'sucking ability' [3], 'swallowing pattern' [24], 'coughs during or after feeding' [19], 'decreased oxygen saturation $\left(\mathrm{SpO}_{2}\right)$ within 3 minutes of feeding' [19], 'vomiting within 5 minutes of feeding' [10], and 'voice change after feeding' [25]. The assessment items were analyzed by retrospective medical record reviews.

'Gestational age' was categorized into below 32 weeks, between 32 weeks and 34 weeks, and between 34 weeks and 37 weeks. 'The Apgar score at 5 minutes' was divided into less than 7 and more than 7 , according to Casey et al. [26]. 'Body weight at birth' was categorized into less than $1,500 \mathrm{~g}$ and more than $1,500 \mathrm{~g}$ [10]. A 'history of pneumonia' was defined as histories of cough, fever over $38.5^{\circ} \mathrm{C}$, dyspnea, and infiltration according to a chest X-ray examination. 'History of apnea' was assessed by a vital sign monitor to determine whether an infant did not breathe over a period of 15 seconds.

'Sucking ability' was measured through non-nutritive sucking using a pacifier. To assess the 'swallowing pattern,' we referred to the Neonatal Oral-Motor Assessment Scale (NOMAS) swallowing test method where nutritive sucking is observed for 5 minutes. The following sucking patterns were diagnosed to be abnormal: disorganized sucking patterns when the preterm infants showed reduced rhythmicity (arrhythmic sucking pattern) and reduced coordination of sucking, swallowing, and breathing (uncoordinated sucking pattern); dysfunctional sucking patterns when they displayed abnormal jaw and tongue movements [24]. 'Coughs during or after feeding' [13] and 'vomiting within 5 minutes of feeding' [10] were also evaluated. 'Decreased oxygen saturation within 3 minutes of feeding' [19] was determined when $\mathrm{SpO}_{2}$ decreased to under 90\% [19]. For 'voice change after feeding, we listened for gurgling or other liquid sounds after feeding [25].

Two rehabilitation doctors participated in the evaluation for inter-rater reliability. Examiner A checked medical histories, and both examiners A and B conducted physical examinations.

Videofluoroscopic swallowing study

We modified the methods of Logemann [13] and New- 
man et al. [5]. Preterm infants were placed on a Tumble Forms Feeder seat at $45^{\circ}$ and radiation was laterally projected. A mixture of barium and milk with a ratio of 1:1 was used. In order to minimize radiation exposure, Xrays were projected for no more than 15 to 30 seconds allowing for one to two swallows. The maximum duration of radiation exposure did not exceed 2 minutes and if an infant showed signs of aspiration prior to those $2 \mathrm{~min}$ utes, testing was discontinued. For infants with a lack of sucking ability, we inserted the formula into the mouth using a 1-mL syringe [5].

Examiner A performed the VFSS by the same method on all infants and both examiners viewed the same VFSS images.

Supraglottic penetration was defined as barium passing the laryngeal vestibule but not the true vocal folds, and subglottic aspiration was defined as barium flowing below the true vocal folds [13]. Supraglottic penetration and subglottic aspiration were ascertained by using the penetration-aspiration scale (PAS) which is determined by two factors: (1) the degrees to which material passes through the airway and (2) whether material is removed from the airway [27].

\section{Item selection}

The impact on supraglottic penetration or subglottic aspiration was established by calculating the odds ratio, comparing the initial assessment items, and the VFSS results. All initial assessment items were established as independent variables and the VFSS results as the dependent variable in logistic regression analyses for which the odds ratio, $95 \%$ confidence intervals, and $\mathrm{p}$-values were calculated. Among the initial assessment items, those with 1.0 or higher odds ratios and p-values $<0.1$ were selected as the final items.

\section{Statistical analysis}

Cutoff values, sensitivity, specificity, and the area under the receiver operating characteristic (ROC) curve (AUC) of the DST-PI were calculated in a ROC curve analysis. For inter-rater reliability, we used the kappa coefficient. According to the VFSS results, the preterm infants were divided into three groups: (1) those who did not show supraglottic penetration or subglottic aspiration, (2) those who displayed supraglottic penetration, and (3) those who exhibited subglottic aspiration. The total DST-PI scores of each group were analyzed by analysis of variance (ANOVA) and Tukey post-hoc test. The correlation between the PAS and total scores was determined using the Spearman correlation coefficient. SAS ver. 9.3 (SAS Institute Inc., Cary, NC, USA) was employed for all statistical analyses.

\section{RESULTS}

Among the numerous reasons of requesting VFSS for the 42 preterm infants ( 24 males, 18 females), decreased $\mathrm{SpO}_{2}$ was the highest with 36 cases. Four cases were requested due to suspicion of aspiration pneumonia and two to remove a feeding tube. The average gestational age was 31 weeks 1 day \pm 2 weeks 5.6 days. Twenty-eight infants (66.7\%) were born before 32 weeks, 7 (16.7\%) between 32 and 34 weeks, and 7 (16.7\%) between 34 and

Table 1. Characteristics of the preterm infants $(n=42)$

\begin{tabular}{|lc|}
\hline \multicolumn{1}{|c}{ Characteristic } & No. \\
\hline Sex & 24 \\
\hline Male & 18 \\
\hline Female & \\
\hline Gestational age (wk) & 28 \\
\hline$<32$ & 7 \\
\hline $32-34$ & 7 \\
\hline $34-37$ & \\
\hline Delivery & 21 \\
\hline Normal vaginal delivery & 21 \\
\hline Cesarean section & \\
\hline Body weight at birth (g) & 23 \\
\hline$<1,500$ & 19 \\
\hline$\geq 1,500$ & \\
\hline Underlying disease & 31 \\
\hline Respiratory distress syndrome & 18 \\
\hline Atrial septal defect & 10 \\
\hline Patent ductus arteriosus & 7 \\
\hline Bronchopulmonary dysplasia & 6 \\
\hline Neonatal seizure & 6 \\
\hline Neonatal jaundice & 4 \\
\hline Brain hemorrhage & 4 \\
\hline Congenital syphilis, rotavirus & 2 \\
\hline Gastroesophageal reflux disease & 2 \\
\hline Chromosome anomaly & \\
\hline
\end{tabular}


37 weeks. It took 59 days on average from the time of the initial request to VFSS testing. The average corrected age at the VFSS was 39 weeks 5 days \pm 6 weeks 4 days. Twentyone were born via vaginal delivery and the other 21 were delivered by cesarean section. The average Apgar score was $8 \pm 2.04$ at 5 minutes. The average body weight at birth was $1,656 \pm 511 \mathrm{~g}$.

When investigating associated diseases, 31 infants (73.8\%) suffered from respiratory distress syndrome, followed by atrial septal defects in 18 (42.9\%), and patent ductus arteriosus in 10 (23.8\%). Seven (16.7\%) displayed bronchopulmonary dysplasia (Table 1). Among the 42 preterm infants, 20 were diagnosed with supraglottic penetration and 9 with subglottic aspiration.

As for the odds ratios with regard to supraglottic penetration or subglottic aspiration of the initial assessment items, 'decreased oxygen saturation within 3 minutes of feeding' was the highest at 11.57. 'Sucking ability,' 'vomiting within 5 minutes of feeding, 'the Apgar score at 5 minutes,' 'body weight at birth,' 'history of ventilator usage,' and 'history of pneumonia' were not statistically significant with $\mathrm{p}$-values greater than 0.1 (Table 2). We selected items with odds ratios greater than 1.0 and p- values less than 0.1 as the final assessment items. These final items were quantitatively assigned, their odds ratios compared, and their scores added up to 10 (Table 3).

The sensitivity and specificity of the DST-PI at 3.25 points were $96.6 \%$ and $76.9 \%$, and at 6.25 points $88.9 \%$ and $75.8 \%$, respectively. The AUC was 0.942 (confidence interval, 0.853-1.000), which indicates a high validity. The average total scores were $2.38 \pm 1.77$ for group 1 , $6.21 \pm 2.02$ for group 2 , and $8.20 \pm 1.68$ for group 3 , statistically significant with $\mathrm{p}<0.05$. The Spearman correlation coefficient between total scores of all preterm infants and the PAS was statistically significant at $0.807(\mathrm{p}<0.001)$. As for inter-rater reliability, the kappa coefficients for 'swallowing pattern,' 'coughs during or after feeding,' 'decreased oxygen saturation within 3 minutes of feeding,' 'voice change after feeding,' and the VFSS report were $0.869,1.000,1.000,0.757$, and 0.883 , respectively, all with statistically significant $\mathrm{p}$-values $<0.001$.

\section{DISCUSSION}

Many studies reported that the symptoms of aspiration are more common in preterm infants than in full-term

Table 2. Logistic regression model for the relationship between the initial DST-PI items and supraglottic penetration or subglottic aspiration

\begin{tabular}{|llll|}
\hline \multicolumn{1}{|c}{ Initial assessment item } & OR & $\mathbf{9 5 \% ~ C I ~}$ & p-value \\
\hline Medical history & & & \\
\hline Gestational age & & & \\
\hline$<32 \mathrm{wk}$ & 8.63 & $1.961-37.941$ & $0.003^{*}$ \\
\hline$<34 \mathrm{wk}$ & 1.88 & $0.354-9.930$ & 0.657 \\
\hline Apgar score at 5 minutes & 2.50 & $0.262-23.864$ & 0.414 \\
\hline Body weight at birth (<1,500 g) & 1.49 & $0.393-5.668$ & 0.555 \\
\hline History of ventilator usage & 2.13 & $0.466-9.771$ & 0.323 \\
\hline History of pneumonia & 3.13 & $0.337-29.086$ & 0.296 \\
\hline History of apnea & 10.80 & $2.358-49.464$ & $0.001^{*}$ \\
\hline History of cyanosis during feeding & 5.89 & $1.105-31.412$ & $0.028^{*}$ \\
\hline Physical examination & & & \\
\hline Sucking ability & 0.64 & $0.093-4.342$ & 0.641 \\
\hline Swallowing pattern & 6.32 & $0.715-55.814$ & $0.071^{*}$ \\
\hline Coughs during or after feeding & 11.20 & $1.284-97.713$ & $0.012^{*}$ \\
\hline Decreased oxygen saturation within 3 minutes of feeding & 11.57 & $1.906-70.237$ & $0.003^{*}$ \\
\hline Vomiting within 5 minutes of feeding & 0.43 & $0.025-7.432$ & 0.550 \\
\hline Voice change after feeding & 8.47 & $0.967-74.167$ & $0.029^{*}$ \\
\hline
\end{tabular}

DST-PI, Dysphagia Screening Test for Preterm Infants; OR, odds ratio; CI, confidence interval. ${ }^{*} \mathrm{p} \leq 0.1$. 
Table 3. Dysphagia Screening Test for Preterm Infants (DST-PI)

\begin{tabular}{|ll}
\hline \multicolumn{1}{|c}{ Assessment } & Score \\
\hline Medical history & \\
\hline Gestational age (wk) & \\
\hline$<32$ & 1.4 \\
\hline$\geq 32$ & 0 \\
\hline History of apnea & 1.7 \\
\hline Yes & 0 \\
\hline No & \\
\hline History of cyanosis during feeding & 0.9 \\
\hline Yes & 0 \\
\hline No & \\
\hline Physical examination & 1.0 \\
\hline Swallowing pattern & 0 \\
\hline Abnormal & \\
\hline Normal & 1.8 \\
\hline Coughs during or after feeding & 0 \\
\hline Yes & \\
\hline No & \\
\hline Decreased oxygen saturation within & 1.8 \\
\hline 3 minutes of feeding (\%) & 0 \\
\hline$<90$ & 1.4 \\
\hline$>90$ & 0 \\
\hline Voice change after feeding & \\
\hline Yes & \\
\hline No & \\
\hline Total & \\
\hline
\end{tabular}

infants $[4,5]$. Dysphagia is due to preterm infants' immaturity and supraglottic penetration can increase the risk for subglottic aspiration [28]. According to the results of Uhm et al. [35] and Bae et al. [2], $40.0 \%$ and $72 \%$ of preterm infants showed signs of aspiration, respectively, while the ratio was $69.0 \%$ in this study.

'Coughs during or after feeding,' 'decreased oxygen saturation within 3 minutes of feeding,' and 'history of apnea' were highly related to dysphagia, consistent with the studies that reported statistical significance for 'gestational age,' 'history of cyanosis during feeding,' 'swallowing pattern,' and 'voice change after feeding.'

In the study of Lee et al. [15], cyanosis with coughs during feeding displayed a higher statistical significance with aspiration than in our study. Delzell et al. [29] reported that aspiration is associated to a low degree with decreased oxygen saturation; however, there was a high correlation between dysphagia and 'decreased oxygen saturation within 3 minutes of feeding' in this study, as also found by Roger et al. [30].

There is a report that indicates a higher frequency of dysphagia of preterm infants born before 32 weeks of gestational age [14]. However, according to Bae et al. [2], preterm infancy with birth before 34 weeks highly affects aspiration. Preterm infants born before 32 weeks were at a higher risk of dysphagia compared to those born after 32 weeks in this study. We suggest that this variation occurred, because maturation of deglutition takes place between 32 and 34 weeks of gestation [14,31].

A disorganized sucking pattern is reported more often in preterm infants than dysfunctional sucking [31], which corresponds with our study that included 7 preterm infants with a disorganized sucking pattern and three with a dysfunctional sucking pattern.

The items 'Apgar score at 5 minutes,' 'body weight at birth, 'history of ventilator usage,' 'history of pneumonia,' 'sucking ability,' and 'vomiting within 5 minutes of feeding' were not statistically significant.

Casey et al. [26] reported that the Apgar score was related to mortality and Simbron et al. [23] stated that 'the Apgar score at 5 minutes' was related to dysphagia. However, corresponding associations were not statistically significant in this study, indicating that the differences in the diagnostic method of the swallowing difficulty are irrelevant. We diagnosed dysphagia through VFSS, whereas Simbron et al. [23] scrutinized abnormal swallowing patterns for this purpose.

Lee et al. [10] reported that dysphagia was more frequent in infants with a very low birth weight, but this relationship was not statistically significant in our study. The subjects were different compared to those described in Lee et al. [10] who displayed desaturation at a gestational age of under 28 weeks. Rommel et al. [8] reported that preterm infants with birth weights under the 10th percentile according to gestational age showed a higher dysphagia frequency for. However, we could not observe this, due to the small number of subjects under the gestational age's 10th percentile.

Greenough and Milner [34] reported that pneumonia, which occurred in $10 \%$ of preterm infants, was more affected by underlying medical diseases than by dysphagia. We considered that the risk of aspiration pneumonia may 
be decreased by defense mechanisms.

Oral food intake and proper oral stimulation aid infant development. There are reports that intubation interrupts the development of the swallowing function $[17,33]$. We assumed that a 'history of ventilator usage' affected dysphagia, but no relationship could be detected. Investigating medical records, periods of ventilator usage were short and none of the preterm infants used one when testing with VFSS.

Rosenbek et al. [27] developed the PAS to determine supraglottic penetration and subglottic aspiration for stroke patients, but Lee et al. [15] applied it to infants. The subjects differed in these studies and this investigation added preterm infants to the list. We found a relationship between total scores of the DST-PI and the PAS using the Spearman correlation coefficient.

Associated diseases were investigated retrospectively through medical records, but there was a limitation due to missing information about disease duration and severity. Large randomized, controlled, and prospective studies are needed to confirm the benefits of the DST-PI.

The sensitivities of the Toronto Bedside Swallowing Screening Test (TOR-BSST) and the Gugging Swallowing Screen (GUSS) which are known as dysphagia screening tests for stroke patients, were $91.3 \%$ and $100.0 \%$, respectively $[20,21]$. The sensitivity of the DST-PI was $96.6 \%$ at 3.25 points. Although the subjects were different compared to the TOR-BSST and GUSS studies, the DST-PI is considered to be useful in a clinical setting. The examination is easy to perform and there is no exposure to radiation as with the VFSS. It is notable that the DST-PI prevents complications, such as pneumonia or developmental delays, by early screening for dysphagia.

\section{CONFLICT OF INTEREST}

No potential conflict of interest relevant to this article was reported.

\section{REFERENCES}

1. Hamilton BE, Minino AM, Martin JA, Kochanek KD, Strobino DM, Guyer B. Annual summary of vital statistics: 2005. Pediatrics 2007;119:345-60.

2. Bae SO, Lee GP, Seo HG, Oh BM, Han TR. Clinical characteristics associated with aspiration or penetra- tion in children with swallowing problem. Ann Rehabil Med 2014;38:734-41.

3. Uhm KE, Yi SH, Chang HJ, Cheon HJ, Kwon JY. Videofluoroscopic swallowing study findings in full-term and preterm infants with Dysphagia. Ann Rehabil Med 2013;37:175-82.

4. Lefton-Greif MA. Pediatric dysphagia. Phys Med Rehabil Clin N Am 2008;19:837-51, ix.

5. Newman LA, Keckley C, Petersen MC, Hamner A. Swallowing function and medical diagnoses in infants suspected of Dysphagia. Pediatrics 2001;108:E106.

6. Yehuda S, Rabinovitz S, Mostofsky DI. Nutritional deficiencies in learning and cognition. J Pediatr Gastroenterol Nutr 2006;43 Suppl 3:S22-5.

7. Martin BJ, Corlew MM, Wood H, Olson D, Golopol LA, Wingo $\mathrm{M}$, et al. The association of swallowing dysfunction and aspiration pneumonia. Dysphagia 1994; 9:1-6.

8. Rommel N, De Meyer AM, Feenstra L, VeeremanWauters G. The complexity of feeding problems in 700 infants and young children presenting to a tertiary care institution. J Pediatr Gastroenterol Nutr 2003;37: 75-84.

9. Rogers B, Arvedson J, Buck G, Smart P, Msall M. Characteristics of dysphagia in children with cerebral palsy. Dysphagia 1994;9:69-73.

10. Lee JH, Chang YS, Yoo HS, Ahn SY, Seo HJ, Choi SH, et al. Swallowing dysfunction in very low birth weight infants with oral feeding desaturation. World J Pediatr 2011;7:337-43.

11. Khoshoo V, Edell D. Previously healthy infants may have increased risk of aspiration during respiratory syncytial viral bronchiolitis. Pediatrics 1999;104:138990.

12. Prasse JE, Kikano GE. An overview of pediatric dysphagia. Clin Pediatr (Phila) 2009;48:247-51.

13. Logemann JA. Manual for the videofluorographic study of swallowing. 2nd ed. Austin: Pro-ED; 1993. p. 65-7.

14. Mizuno K, Ueda A. The maturation and coordination of sucking, swallowing, and respiration in preterm infants. J Pediatr 2003;142:36-40.

15. Lee KW, Kim SB, Lee JH, Kim TH, Han DW, Kim MJ. Evaluating the clinical symptoms of neonates with suspected dysphagia. J Korean Acad Rehabil Med 2011;35:265-71. 
16. Zerilli KS, Stefans VA, DiPietro MA. Protocol for the use of videofluoroscopy in pediatric swallowing dysfunction. Am J Occup Ther 1990;44:441-6.

17. Hawdon JM, Beauregard N, Slattery J, Kennedy G. Identification of neonates at risk of developing feeding problems in infancy. Dev Med Child Neurol 2000;42: 235-9.

18. Morgan AT, Omahoney R, Francis H. The use of pulse oximetry as a screening assessment for paediatric neurogenic dysphagia. Dev Neurorehabil 2008;11:2538.

19. Weir K, McMahon S, Barry L, Masters IB, Chang AB. Clinical signs and symptoms of oropharyngeal aspiration and dysphagia in children. Eur Respir J 2009;33: 604-11.

20. Trapl M, Enderle P, Nowotny M, Teuschl Y, Matz K, Dachenhausen A, et al. Dysphagia bedside screening for acute-stroke patients: the Gugging Swallowing Screen. Stroke 2007;38:2948-52.

21. Martino R, Silver F, Teasell R, Bayley M, Nicholson G, Streiner DL, et al. The Toronto Bedside Swallowing Screening Test (TOR-BSST): development and validation of a dysphagia screening tool for patients with stroke. Stroke 2009;40:555-61.

22. DeMatteo C, Matovich D, Hjartarson A. Comparison of clinical and videofluoroscopic evaluation of children with feeding and swallowing difficulties. Dev Med Child Neurol 2005;47:149-57.

23. Simbron AV, Sorbera-Ferrer L, Gomez de Ferraris ME, Carranza ML. Cyclical pattern of non-nutritive sucking in normal and high-risk neonates. Acta Odontol Latinoam 2013;26:150-4.

24. Palmer MM, Crawley K, Blanco IA. Neonatal OralMotor Assessment scale: a reliability study. J Perinatol 1993;13:28-35.

25. Warms T, Richards J. "Wet Voice" as a predictor of penetration and aspiration in oropharyngeal dysphagia. Dysphagia 2000;15:84-8.

26. Casey BM, McIntire DD, Leveno KJ. The continuing value of the Apgar score for the assessment of newborn infants. N Engl J Med 2001;344:467-71.

27. Rosenbek JC, Robbins JA, Roecker EB, Coyle JL, Wood JL. A penetration-aspiration scale. Dysphagia 1996;11: 93-8.

28. Delzell PB, Kraus RA, Gaisie G, Lerner GE. Laryngeal penetration: a predictor of aspiration in infants? Pediatr Radiol 1999;29:762-5.

29. Wang TG, Chang YC, Chen SY, Hsiao TY. Pulse oximetry does not reliably detect aspiration on videofluoroscopic swallowing study. Arch Phys Med Rehabil 2005;86:730-4.

30. Rogers B, Msall M, Shucard D. Hypoxemia during oral feedings in adults with dysphagia and severe neurological disabilities. Dysphagia 1993;8:43-8.

31. Bu'Lock F, Woolridge MW, Baum JD. Development of co-ordination of sucking, swallowing and breathing: ultrasound study of term and preterm infants. Dev Med Child Neurol 1990;32:669-78.

32. da Costa SP, van der Schans CP, Zweens MJ, Boelema SR, van der Meij E, Boerman MA, et al. The development of sucking patterns in preterm, small-for-gestational age infants. J Pediatr 2010;157:603-9, 609.

33. Pagliaro CL, Buhler KE, Ibidi SM, Limongi SC. Dietary transition difficulties in preterm infants: critical literature review. J Pediatr (Rio J) 2016;92:7-14.

34. Greenough A, Milner AD. Neonatal respiratory disorders. 2nd ed. London: CRC Press; 2003. p. 278-9.

35. Arvedson J, Clark H, Lazarus C, Schooling T, Frymark T. Evidence-based systematic review: effects of oral motor interventions on feeding and swallowing in preterm infants. Am J Speech Lang Pathol 2010;19: 321-40. 